\title{
Primary outcomes of combined cataract extraction technique with Ab-Interno trabeculectomy and endoscopic Cyclophotocoagulation in patients with primary open angle Glaucoma
}

\author{
Juan Carlos Izquierdo 1,2,3, Josefina Mejías', Laura Cañola-R¹, Natalia Agudelo and Bárbara Rubio ${ }^{1 *}$ (i)
}

\begin{abstract}
Background: Glaucoma surgery have been developed to lower intraocular pressure in a less invasive manner than traditional glaucoma surgery. The purpose of this article is to determine the outcome of using combined phacoemulsification technique, ab-interno trabeculectomy dual blade and endoscopic cyclophotocoagulation (ECP) surgeries in patients with primary open angle glaucoma.

Methods: A retrospective case series was performed on 27 consecutive eyes with both primary open-angle glaucoma (POAG) and cataract; each eye was treated with combined phacoemulsification, ab-interno trabeculectomy-Kahook Dual Blade and Endocyclophotocoagulation at Instituto de ojos Oftalmosalud, Lima, Peru, between April 2017 and May 2017. Inclusion criteria: 1) Patients with uncontrolled mild to advanced POAG (according to Glaucoma Grading Scale HODAPP) 2) cataract condition 3) treatment with two or more glaucoma medications due to rapid progression in the visual fields (at least two in a short period of time). Intraocular pressure (IOP), best corrected visual acuity (BCVA) logMAR and number of glaucoma medications were recorded prior to the study, at day 1, week 1, and 1,3,6 and 9 months after surgery. Primary outcome measure was surgical success defined in terms of IOP $<14 \mathrm{mmHg}$ either with no medications (complete success) or with medications (qualified success).

Results: A total of 27 eyes from 27 patients were included. The mean basal IOP was $17.0 \pm 3.7 \mathrm{mmHg}$ and postoperatively was $11.6 \pm 1.9 \mathrm{mmHg}$ and $11.4 \pm 1.8 \mathrm{mmHg}(P<0.001)$ at 6 and 9 months respectively. Glaucoma medications decreased from $1.9 \pm 1.4$ to $0.56 \pm 1.05$ at 9 month follow-ups $(P<0.001)$. Preoperative best corrected visual acuity (BCVA) showed and improvement from $0.4 \pm 0.4$ LogMAR to $0.2 \pm 0.4 \log M A R$ at 9 months. The main complication was blood reflux intra-operatively (66.7\%), which resolved without re-operation. The mean IOP was reduced by $32.9 \%$ from baseline and the surgical success was $92,6 \%$, (complete success $70,3 \%$ and qualified success $29,6 \%)$ at 9 months.

(Continued on next page)
\end{abstract}

\footnotetext{
* Correspondence: rubio.barbara@gmail.com

${ }^{1}$ Glaucoma Research Department, Instituto de Ojos Oftalmosalud, Lima, Peru

Full list of author information is available at the end of the article
}

(C) The Author(s). 2020 Open Access This article is licensed under a Creative Commons Attribution 4.0 International License, which permits use, sharing, adaptation, distribution and reproduction in any medium or format, as long as you give appropriate credit to the original author(s) and the source, provide a link to the Creative Commons licence, and indicate if changes were made. The images or other third party material in this article are included in the article's Creative Commons licence, unless indicated otherwise in a credit line to the material. If material is not included in the article's Creative Commons licence and your intended use is not permitted by statutory regulation or exceeds the permitted use, you will need to obtain permission directly from the copyright holder. To view a copy of this licence, visit http://creativecommons.org/licenses/by/4.0/ The Creative Commons Public Domain Dedication waiver (http://creativecommons.org/publicdomain/zero/1.0/) applies to the data made available in this article, unless otherwise stated in a credit line to the data. 
(Continued from previous page)

Conclusions: In patients with POAG, combined treatment with phacoemulsification, ab-interno trabeculectomy and endoscopic cyclophotocoagulation effectively reduced IOP and glaucoma medication dependence.

Keywords: MIGS, Endociclophotocoagulation, Micro-incisional glaucoma surgery, Trabecular meshwork, Kahook dual blade

\section{Background}

In geriatrics, it is common to find in patients with both cataract and glaucoma, both of which can be treated with combined phacoemulsification and glaucoma surgery to improve vision and avoid progression while improving cost-effectiveness [1].

The pathophysiology of open angle glaucoma is described as resistance outflow of aqueous humour, which is mainly the juxtacanalicular portion of the trabecular meshwork (TM). By performing an ab-interno trabeculectomy, the disease portion is removed and the conventional outflow pathway is enhanced with posterior reduction of intraocular pressure (IOP) [2-5].

Endoscopic cyclophotocoagulation is one of the safest armamentarium therapies for glaucoma; the ciliary processes are visualized directly using diode laser energy treated precisely until shrinkage and whitening occur. This therapy causes a reduction of aqueous humour production which decreases IOP effectively without the complications described for cycloablative procedures such as persistent hypotony, phthisis, inflammation or visual loss [6, 7].

Gold standard filtering surgery is associated with high rate of immediate and late complications as reported in the TVT study. For this reason, there is a trend to treat glaucoma patients with minimally-invasive procedures when maximal tolerated medical therapy fails to control visual field loss in initial or moderate glaucoma.

In this study a combined treatment of Phacoemulfisication, ab-interno trabeculectomy (Kahook) and ECP was performed to treat uncontrolled POAG and double mechanism for reducing IOP was expected. An update of the technique, reduction of IOP, glaucoma medications and visual acuity were evaluated.

\section{Methods}

This retrospective case series comprised 27 eyes of 27 patients, with uncontrolled open-angle glaucoma (POAG) and cataract, having combined phacoemulsification, ab-interno trabeculectomy with Kahook Dual Blade (KDB) (New World Medical Inc., Rancho Cucamonga, CA, USA) and ECP, at Instituto de ojos Oftalmosalud, Lima, Peru, between April 2017 and May 2017. The abinterno trabeculectomy was performed 90-120 degrees, and endoscopic cyclophotocoagulation was performed
360 degrees through 2 site corneal incisions. The mean duration of the follow-up period was 9 months.

The study was approved by the Ethics Committee of the Instituto de Ojos Oftalmosalud, in accordance with the Declaration of Helsinki. All patients provided written informed consent forms prior to enrolment.

Inclusion Criteria: Glaucoma patients with uncontrolled POAG from mild to advanced, according to Glaucoma Grading Scale (HODAPP), cataract condition, treatment with two or more glaucoma medications; uncontrolled was defined as progression in at least 2 visual fields and/ or retinal nerve fibre layer thinning in spfectral domain optical coherence tomography (sdOCT),

Exclusion Criteria: history of glaucoma surgery, any subsequent glaucoma surgery in the follow-up period, narrow angles or closed angle glaucoma, neovascular, uveitic or other secondary glaucoma, retinal or neurophthalmic diseases.

The intraocular pressure (IOP), best corrected visual acuity (BCVA) LogMAR and number of glaucoma medications were recorded prior to treatment, at day 1 , week 1, and 1, 3, 6 and 9 months after surgery. At each visit, the IOP was measured with a Goldmann applanation tonometer. The intra and postoperative complications were recorded. Success was defined as IOP $<14 \mathrm{mmHg}$ with or without glaucoma medication.

\section{Surgical modified technique}

All procedures were performed by the same surgeon (JCI). Firstly, phacoemulsification and IOL implantation was performed using 2,2 $\mathrm{mm}$ keratome and $1.20 \mathrm{~mm}$ side-port blade, the anterior chamber was filled with preservative-free lidocaine $1 \%$, and an ophthalmic viscosurgical device (OVD) (Healon GV; Abbott Medical Optics, Santa Ana, CA, USA). Continuous curvilinear capsulorhexis (CCC) was created with a capsulorhexis fórceps and lens segmentation was performed by using a stop and chop technique. Surgery was completed by implantation of an intraocular lens (IOL) in the capsular bag after successful removal of the lens cortex.

Secondly, ECP (Endo Optiks ${ }^{\circ}$ E2 Ophthalmic Laser Endoscopy System, Beaver-Visitec International, Inc. USA) containing an endoscope, an illumination source, the diode LASER $(810 \mathrm{~nm})$ and a helium-neon aiming beam, was inserted into the anterior chamber via the main corneal incision. Once the intraocular lens (IOL) 
was positioned in the bag, viscoelastic was injected to expand the sulcus behind the iris, and the diode laser ablation of the ciliary processes was performed under direct visualization via a $20 \mathrm{G}$ endoscope. In order to reach 360 degrees of the ciliary processes, a second incision 180 degrees away from the initial incision was made. The physical goals of treatment were to whiten the ciliary processes and cause visible shrinkage of the tissue, avoiding rupture. The 2-site corneal incisions 360 degrees were treated successfully with $0.2 \mathrm{~W}$ energy on continues mode (Fig. 1).

Finally, a $2.2 \mathrm{~mm}$ wide iris planar clear corneal incision is fashioned approximately $2 \mathrm{~mm}$ anterior to the surgical limbus and viscoelastic was used in the anterior chamber. The patient's head was rotated 40 degrees away from the surgeon and the microscope was tilted in the opposite direction for gonioscopic visualization, with the goniolens (AVG; Surgical Gonio Lens, Volk Alcon, Mentor, OH, USA). Trypan blue was use to stain the TM. The Kahook dual-blade (KDB; New World Medical, Rancho Cucamonga, CA, USA) was engaged in the TM just anterior to the scleral spur for a more pointed entry into the meshwork and was advanced 90 degrees parallel toward the wall of the canal. Intracameral dexamethasone 0.8 $\mathrm{mg} / 0.2 \mathrm{ml}$ was administered to all patients in addition to standard cataract antibiotic prophylaxis (intracameral cefuroxime $1.0 \mathrm{mg} / 0.1 \mathrm{ml}$ ). The corneal incisions were then closed with 10-0 nylon (Fig. 2).

Postoperative care routinely included tobramycin 3 $\mathrm{mg} / \mathrm{ml}$ and dexamethasone $1 \mathrm{mg} / \mathrm{ml}$ (Trazidex, Sophia, México) 6 times daily tapered over 1 week, and pilocarpine 1\% (Pil, Sophia, México) 3 to 4 times daily tapered over 4 weeks. In all cases, the glaucoma medication was discontinued at the time of surgery and restarted in selected cases according to IOP.

\section{Statistical analysis}

To compare the changes in IOP according to the observation period, the non-parametric Friedman test was used, followed by a post-hoc Nemenyi multiple comparison test. For change in the number of glaucoma medications, the signed test for paired samples was used. Statistical tests we considered significant if $p$ value was less than 0.05 . The analysis was done with statistical software R, versión 3.4.3 (https://www.r-project.org/).

\section{Results}

This study included 27 eyes from 27 patients who underwent the combined surgical procedure and were followed for at least 9 months. Mean age was $69.1 \pm 8.09$ (range: 53-85) years old. A total of 16 females (59.2\%) and 11 males (40.7\%), 10 (37\%) right eyes and 17 (62.9\%) left eyes were analysed.

All eyes with POAG were classified into 3 groups according to Glaucoma Grading Scale (HODAPP): 10 (37\%) eyes were mild, 10 (37\%) eyes moderate, and 7 (25.9\%) eyes advanced. All 3 categories had a reduction in IOP at 9 month follow-ups; however, multiple comparisons with Nemenyi test after Friedman test showed a statistically significant improvement at 3 months $(p=0$, $010)$ in the mild glaucoma group, at 9 months for the moderate glaucoma group $(p=0.031)$ and without statistically significant improvement in the advanced glaucoma group in any follow-up time, which can be attributed for the smaller sample size of this group. At 9 months, IOP reduction was $7.1 \mathrm{mmHg}$ in the mild group, $4.2 \mathrm{mmHg}$ in the moderate glaucoma group and $6.6 \mathrm{mmHg}$ in the advanced glaucoma. (Fig. 3).

\section{Intraocular pressure}

The mean preoperative IOP was $17.0 \mathrm{mmHg}[ \pm 3.7]$ and the postoperative IOP were $15.0 \mathrm{mmHg}[ \pm 5.3], 13.4$

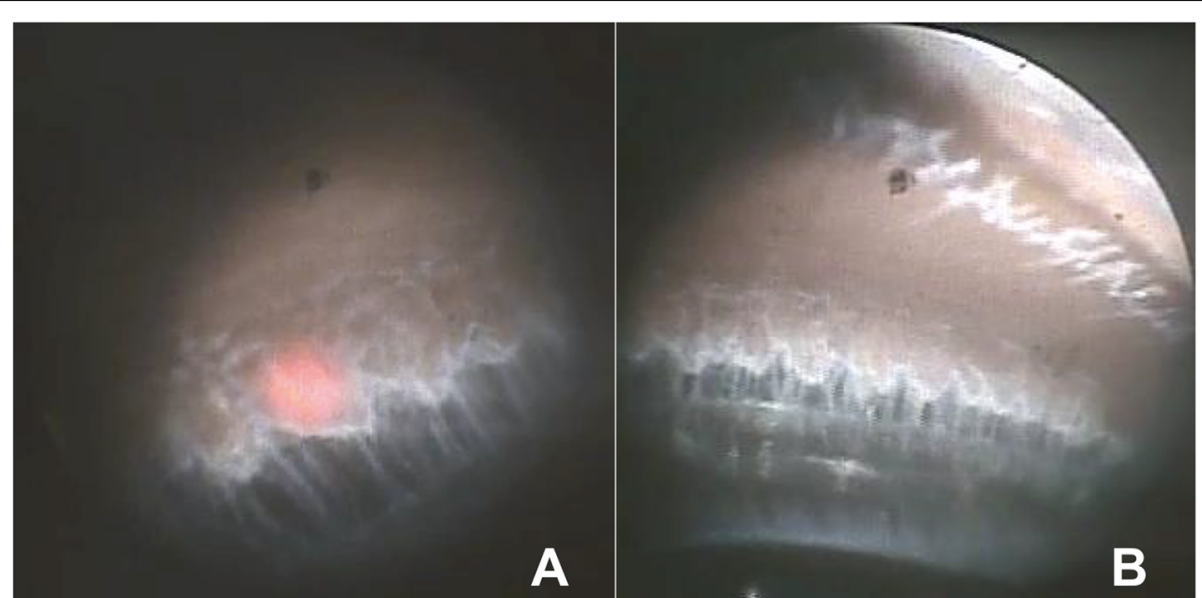

Fig. 1 Endocyclophotocoagulation. Ablation of the ciliary processes. The physical goals of treatment were to whiten the ciliary processes and cause visible shrinkage of the tissue, avoiding rupture 


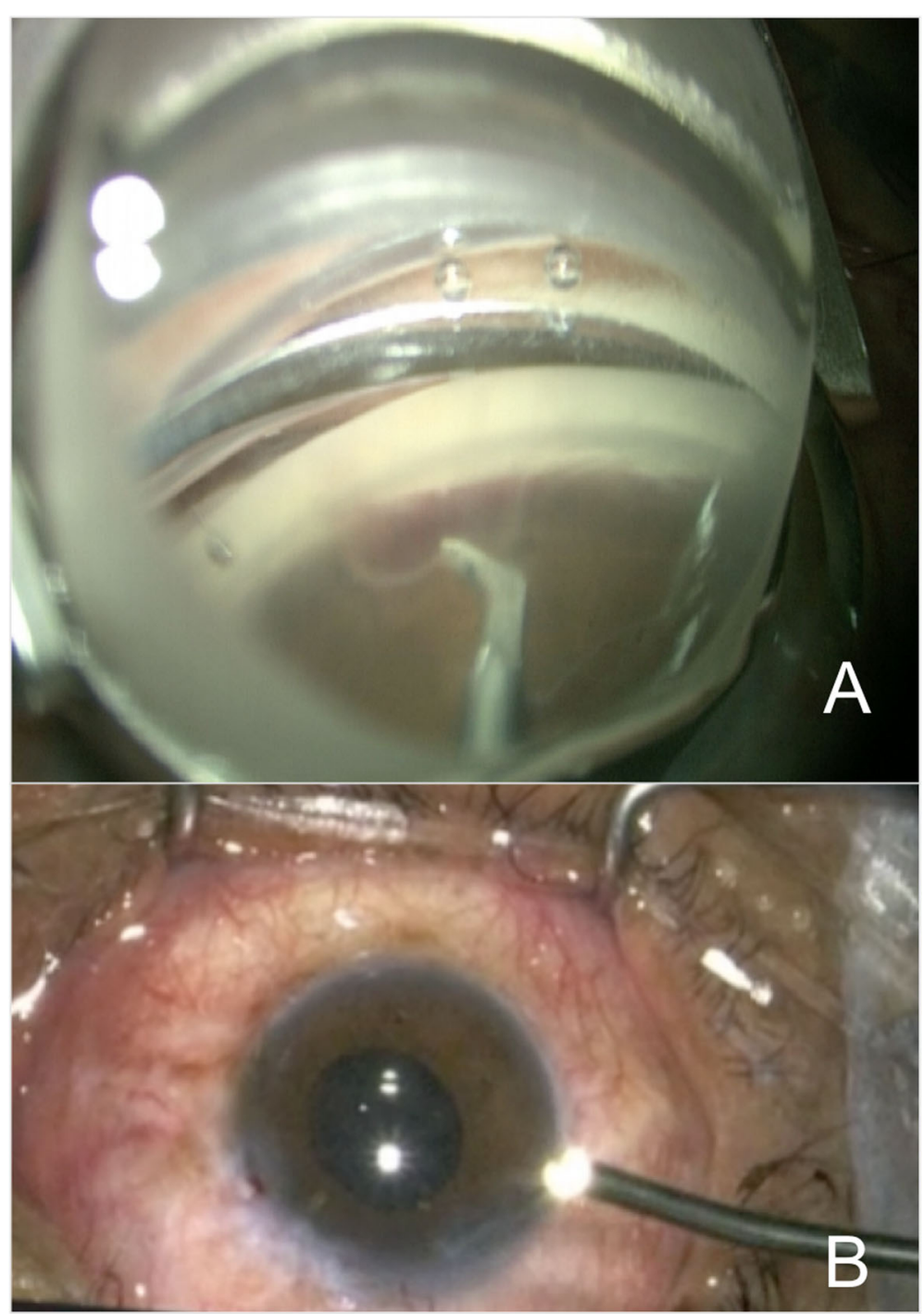

Fig. 2 Steps of the surgery. a.- The Kahook dual-blade was engaged in the TM and was advanced 90 degrees parallel toward the wall of the canal. b.- Secondly, ECP containing an endoscope, an illumination source, the diode LASER $(810 \mathrm{~nm})$ and a helium-neon aiming beam, was inserted into the anterior chamber via the main corneal incision

$\mathrm{mmHg}[ \pm 4.1], 12.1 \mathrm{mmHg}[ \pm 1.9], 11.6 \mathrm{mmHg}$ [ \pm 1.9.], $11.4 \mathrm{mmHg}[ \pm 1.8]$ at 1 week, $1,3,6$, and 9 months respectively, $(p<0.001)$. The mean IOP was reduced by $32.9 \%$ from baseline and the success was $77.8 \%$ in the first month and $92.6 \%$ (complete success $70,3 \%$ and qualified success $29,6 \%$ ) at 9 month follow-ups. (Fig. 4).

\section{Medication outcomes}

At 9 months, preoperative glaucoma medication was $1.9[ \pm 1.41]$ and postoperatively was $0.56[ \pm 1.05]$. The number of postoperative glaucoma medication was significantly reduced; 19 (70.3\%) eyes were without glaucoma medication, $4(14.8 \%)$ eyes with 1 medication, $4(7.4 \%)$ eyes with 2 medications, 1 (3.7\%) eye with 3 medications and 1 (3.7\%) eye with 4 medications at 9 months $(P<0.001)$. (Fig. 5$)$.

Visual acuity outcomes Preoperative best corrected visual acuity (BCVA) showed and improvement from $0.4 \pm$ $0.4 \operatorname{LogMAR}$ to $0.2 \pm 0.4 \operatorname{LogMAR}$ at 9 months with no statistically significant differences $(p>0.05)$.

Postoperative complications The most common complications included: 1$)$ hyphema $(66,7 \%)$, found during week 1 and resolved spontaneously in all cases at 1 month of follow up 2) Intraoperative reflux bleeding was observed in all cases, but stopped by the time the surgery was completed 3) corneal edema (7.4\%), 92,6\% with no complications at 1 month 4) Transient hypotony 


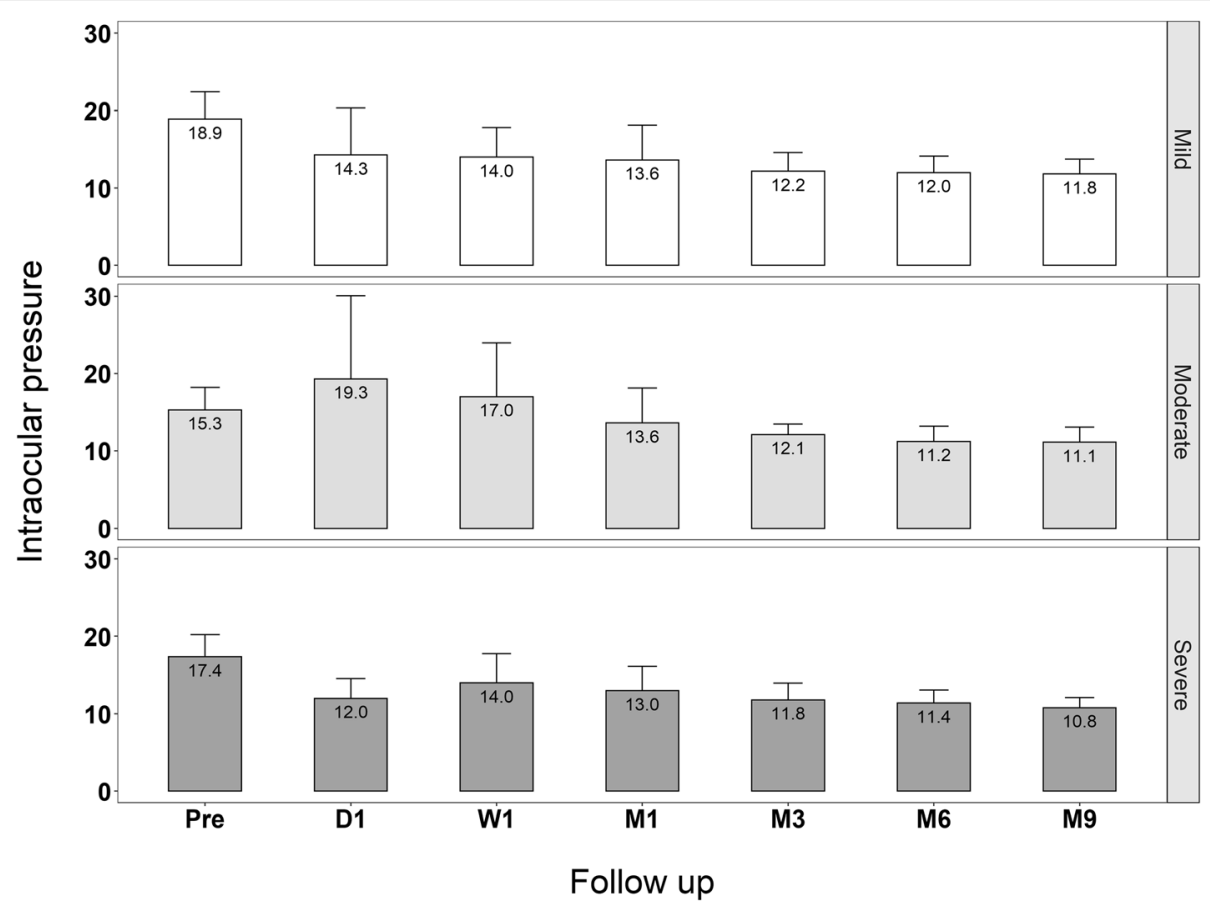

Fig. 3 Comparison of IOP vs Follow-up time. All eyes with POAG were classified into 3 groups: mild, moderate and advanced. At 9 months, IOP reduction was $7.1 \mathrm{mmHg}$ in the mild group, $4.2 \mathrm{mmHg}$ in the moderate glaucoma group and $6.6 \mathrm{mmHg}$ in the advanced glaucoma

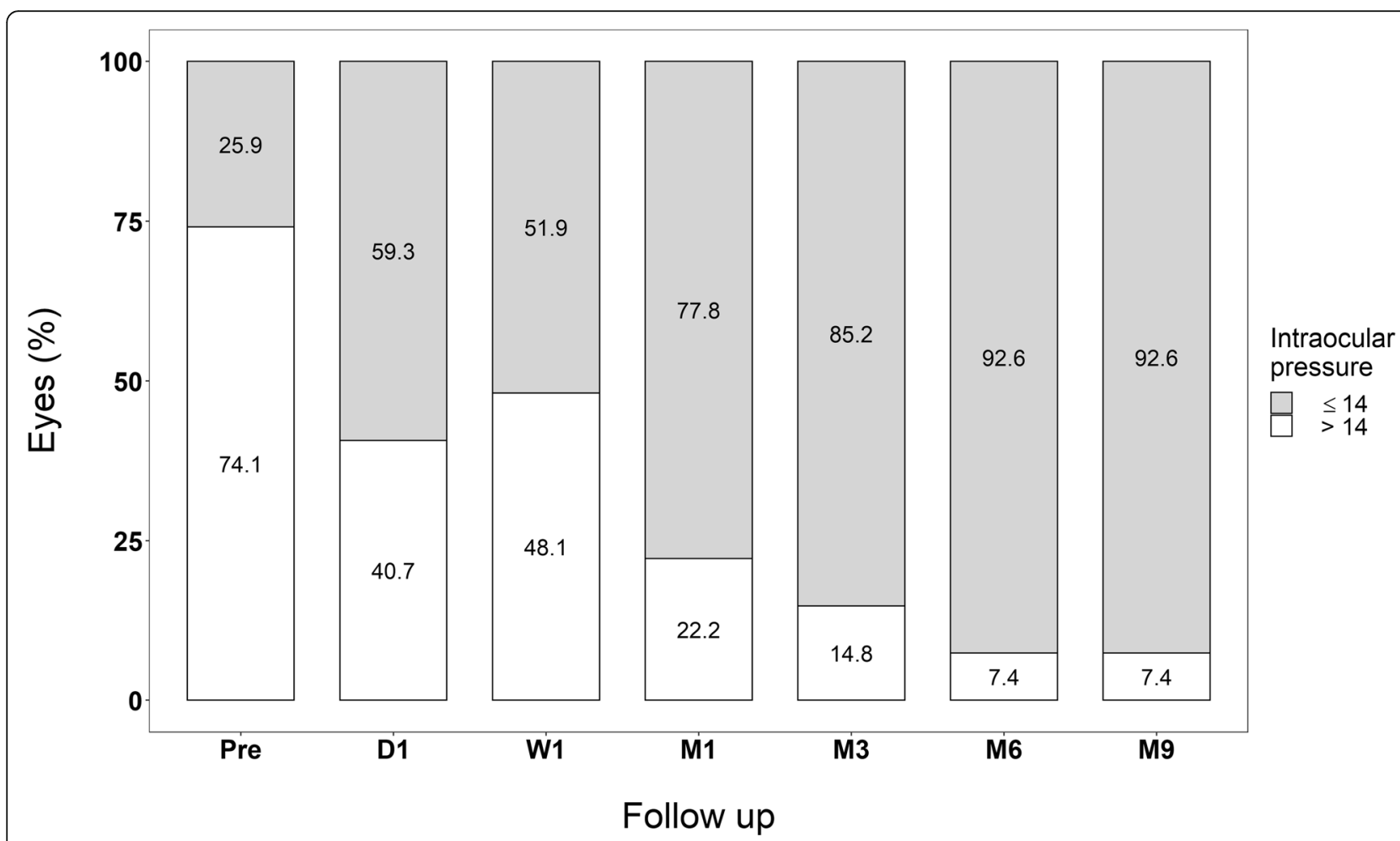

Fig. 4 Percentage of eyes with Intraocular Pressure under $14 \mathrm{mmHg}$. The mean preoperative IOP was $17.0 \mathrm{mmHg}[ \pm 3.7]$. and the postoperative IOP were $15.0 \mathrm{mmHg}[ \pm 5.3], 13.4 \mathrm{mmHg}[ \pm 4.1], 12.1 \mathrm{mmHg}[ \pm 1.9], 11.6 \mathrm{mmHg}[ \pm 1.9], 11.4 \mathrm{mmHg}[ \pm 1.8]$ at 1 week, 1, 3, 6, and 9 months respectively, $(p<0.001)$ 


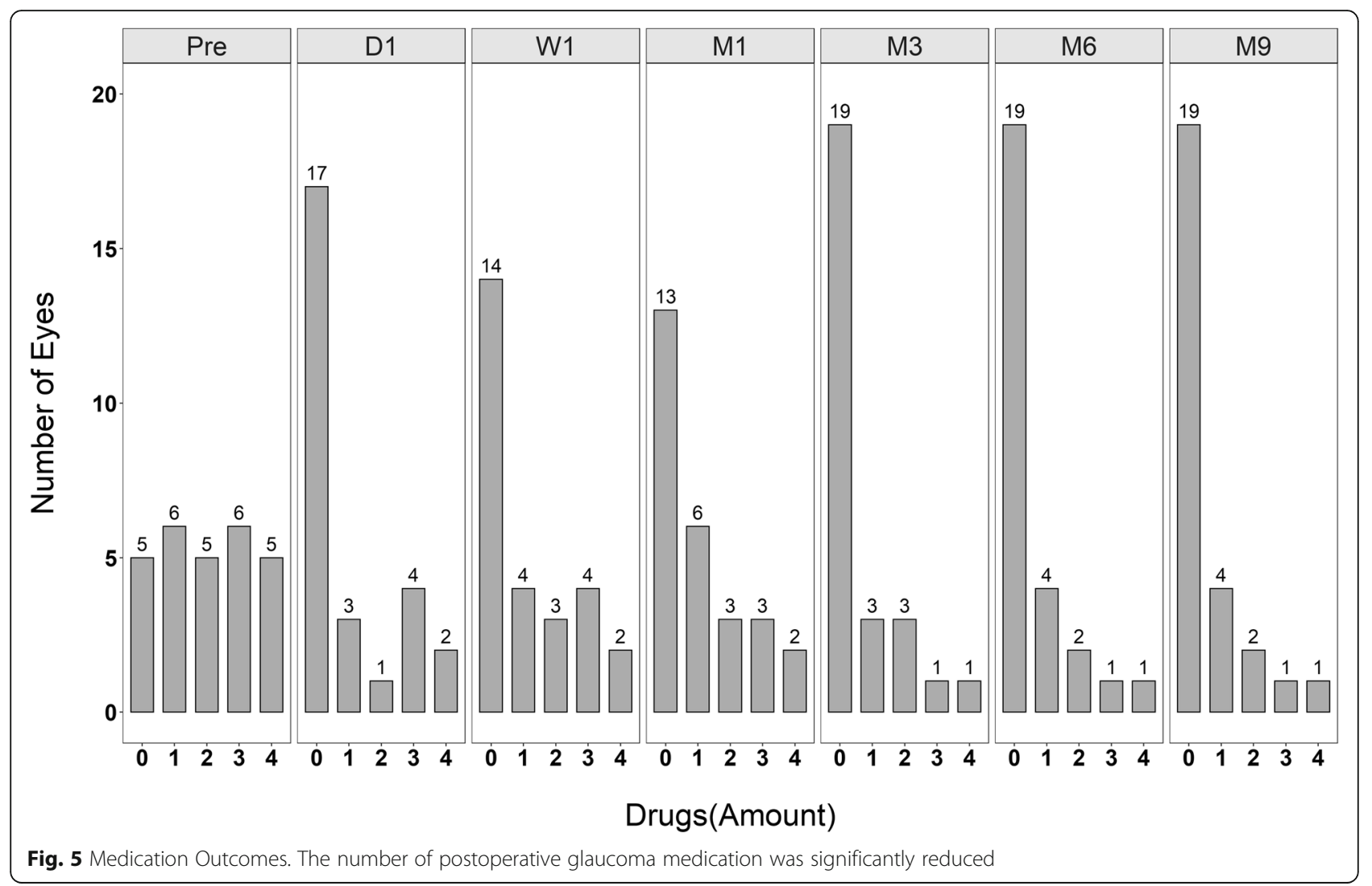

(3,7\%) 5) Temporary IOP spike (6\%). At 3 months, no complication were reported. Complications such as iris injury, corneal descompensation, corneal injury, cyclodialysis, choroidal hemorrhage or endophthalmitis were not found.

\section{Discussion}

This retrospective study of patients with uncontrolled POAG at different stages of the disease showed a reduction of IOP and glaucoma medication with stable, best corrected visual acuity at 9 month follow-ups with combined, minimally-invasive procedures consisting of phaco, ab-interno trabeculectomy and ECP.

Cataract extraction as a stand alone procedure does not provide a significant reduction of IOP in patients with primary open angle glaucoma [1], therefore a combined treatment with glaucoma surgery is almost always the choice for adequate control of the intraocular pressure. The available evidence suggests at most a modest reduction in IOP from cataract extraction around 1.5-3 $\mathrm{mmHg}$ [8] possibly via decompression or mechanical stretch of the TM and Schlemm's canal [7]. Siegel et al. demonstrated a statistically significant difference between the combined phaco-ECP group versus phaco alone [9].

The combination of ECP with phacoemulsification and ab-interno trabeculectomy with phacoemulsification has been studied [10]. Kaplowitz K. et al. described that ECP used for POAG decreases IOP by $8-47 \%$, to a final average near $15 \mathrm{mmHg}$ [11]. Clement et al. combined phacoECP and observed IOP reductions up to $69 \%$, the mean reduction of $23.9 \% 12$ months after treatment $[7,12]$.

A trial by Berke et al. compared 626 eyes treated with phacoemulsification-ECP, where 81 eyes underwent phacoemulsification alone. The follow-up period ranged from 6 months to 5.5 years. In the phacoemulsification-ECP group, mean IOP decreased $3.4 \mathrm{mmHg}$, from 19.1 to 15.7 $\mathrm{mmHg}$. In the control group, mean IOP increased 0.7 $\mathrm{mmHg}$, from 18.9 to $18.2 \mathrm{mmHg}$. More significantly, the number of preoperative glaucoma medications decreased from a mean of 1.53 to 0.65 at the end of the follow-up period in the phacoemulsification-ECP group. There was no visual loss or significant adverse events postoperatively [6]. In our study, the preoperative best corrected visual acuity (BCVA) showed an improvement from preoperative value of $0.4[ \pm 0.4] \operatorname{LogMAR}$ to $0.2[ \pm 0.4] \operatorname{LogMAR}$ at 9 months with no statistically significant differences.

In our combined study, the mean IOP was reduced $32.9 \%$ from baseline and the qualified success was $92.6 \%$ at 9 months. Morales et al., with Phaco-ECP, reported the results obtained for IOP lowering to $15 \mathrm{mmHg}$ and report an absolute success of $11.9 \%$ with a qualified success of $72.3 \%$ [13]. A retrospective Brazilian study on 247 patients, defined success based on IOP $21 \mathrm{mmHg}$ 
with 3 years of follow-up reported the corresponding rates were $55.7 \%$ for absolute success and $90.7 \%$ for qualified success [14].

The Kahook dual blade shows promise as a refined and economical device for the treatment of glaucoma [3]. Salinas et al. studied 53 eyes and the mean IOP decreased from $18.4 \pm 6.1 \mathrm{mmHg}$ at baseline to $13.9 \pm 3.5 \mathrm{mmHg}$ at 6 month follow-ups $(23.9 \%$ reduction, $p<0.001)$; At 6 months, $63.5 \%$ achieved an IOP $\leq 14 \mathrm{mmHg}$ and the mean number of glaucoma medications was reduced $1.2 \pm 1.3$ compared to baseline $(P<0.001)$, a reduction of $36.6 \%$ was found [15]. With the combined procedures used in ours study, the mean IOP decreased from $17.0 \pm 3.7 \mathrm{mmHg}$ at baseline to $11.6 \pm 1.9 \mathrm{mmHg}$ at 6 months $(31.7 \%$ reduction, $P<0.001$ ), and an IOP of $11.4 \pm 1.8 \mathrm{mmHg}$ at 9 months (32.9\% reduction, $P<0.001$ ). The IOP was significantly reduced $(P<0.001)$. The mean number of glaucoma medications used was reduced from $1.90 \pm 1.41$ at baseline pre-op to $0.56 \pm 1.05$ (29.5\% reduction) at 9 months, with statistically significant improvement $(P<0.001)$.

In a preclinical study of human donor of corneoscleral rims; SooHoo et al. used the dual blade device to incise TM and compare with trabectome. Dual blade showed more complete TM tissue removal with no significant damage to adjacent tissues [3]. Seibol et al., a laboratory evaluation in a human eye perfusion model demonstrated that trabectome treatment across $117.5 \pm$ 12.6 degrees resulted in a decrease of IOP from $18.8 \pm$ $1.7 \mathrm{mmHg}$ to $11.3 \pm 1.0 \mathrm{mmHg}(P<.01)$ and with dual blade device treatment across $157.5 \pm 26.3$ degrees, resulted in a decrease of IOP from $18.3 \pm 3.0 \mathrm{mmHg}$ to $11.0 \pm 2.2 \mathrm{mmHg}(p<0.01)$. The novel dual blade device demonstrated a more complete removal of TM without residual TM leaflets or damage to surrounding tissues and significantly reduced $\mathrm{IOP}^{17}$.

Kaplowitz et al., showed that ab-interno trabeculectomy can be expected to lower the IOP by approximately $36 \%$ to a final mean IOP around $16 \mathrm{mmHg}$ while decreasing the number of medications by less than one [11]. Fallano et al. used a combined treatment of phaco-trabectome with $18 \%$ reduction in $\mathrm{IOP}^{2}$. The cases of Trabectome combined with phacoemulsification showed a decrease in IOP from a preoperative mean of $20.0 \pm 6.2 \mathrm{mmHg}$ to a mean of $15.9 \pm 3.3$ $\mathrm{mmHg}$ at 12 months $(n=45)$, a decrease of $18 \%$ [3]. Francis et al. studied 304 patients treated with combined phacotrabectome surgery; the mean IOP decrease from $20.0 \pm$ $6.3 \mathrm{mmHg}$ to $14.8 \pm 3.5 \mathrm{mmHg}$ at 6 months and $15.5 \pm 2.9$ $\mathrm{mmHg}$ at 1 year. The mean number of glaucoma medications was reduced from $2.65 \pm 1.13$ to $1.76 \pm 1.25$ at 6 months and $1.44 \pm 1.29$ at 1 year [1].

Dang et al. combined trabectome and phacotrabectome and divided the patients into 4 groups depending on glaucoma severity. The group with the higher glaucoma severity index (GI) had an IOP reduction of $2.34 \pm 0.19 \mathrm{mmHg}$ more than the group with lower glaucoma severity index [16]. In our study, all subcategories showed a significant reduction in IOP 9 months after combined surgery. The IOP of the mild glaucoma group was reduced from 18.9 to $11.8 \mathrm{mmHg}$, from 15.3 to $11.1 \mathrm{mmHg}$ in the moderate group and from 17.4 to $10.8 \mathrm{mmHg}$ in the advanced group.

The review and meta-analysis of Phaco-ECP from Kaplowitz et al., showed the most common complication was hyphema, similar to the present study, and the second most common complication was peripheral anterior synechiae in $24 \%$ of the patients. The most serious complication was hypotony $0.09 \%$ of all reposted cases [11]. With the use of Trabectome, SooHoo et al. found that all patients with transitory hyphema resolved after 6.4 days [3]. In our study, the most common complications included: hyphema 18 (66.7\%), intraoperative blending (observed in all cases), corneal edema (7.4\%), transient hypotony $(3,7 \%)$ and temporary IOP spike $(6 \%)$ with no vision sequelae and no reoperations.

The weakness of the study were: the retrospective nature, low sample study and lack of control group.

\section{Conclusion}

Cataract extraction with phacoemulsification combined with ab interno trabeculectomy and endoscopic cyclophotocoagulation effectively reduced IOP and dependence on glaucoma medications and showed high safety profile and stable best corrected visual acuity in patients with uncontrolled open angle glaucoma. Further study is needed to compare this combination treatment with the gold standard filtration surgery.

\section{Abbreviations}

BCVA: Best Correted Visual Acuity; CCC: Continuous Curvilinear Capsulorhexis; ECP: Endoscopic cyclophotocoagulation; IOP: Intraocular pressure; IOL: Intraocular Lens; KDB: Kahook Dual Blade; LogMAR: Logarithm of the mínimum angle of resolution; MIGS: Minimally Invasive Glaucoma Surgery; OVD: Ophthalmic Viscosurgical Device; POAG: Primary Open-angle Glaucoma; PHACO: Phacoemulsificiation; SdOCT: Spectral Domain Optical Coherence Tomography; TM: Trabecular Meshwork

\section{Acknowledgements \\ To Jose Chauca and Carmen Maldonado for statistical analysis and technical support.}

\section{Authors' contributions}

$\mathrm{JCl}$ - conception and desing of the study. LCR- data acquisition and analysis. JM- data analysis and study revision. NA- drafting and revision of study. BRdrafting and revision of study. All authors read and approved the final study.

\section{Funding}

No funding or grant support.

Availability of Data and Materials

The datasets used and analysed during this study are available via the corresponding author at reasonable request.

Ethics approval and consent to participate

The study was approved by the Ethics Committee of the Instituto de Ojos Oftalmosalud. All research was conducted in accordance with the 
Declaration of Helsinki. All participants provided written informed consent forms prior to enrolment. This report does not contain any personal information that could lead to the identification of the patient. We do not require any administrative permissions and/or licenses to access the data used in our research.

\section{Consent for publication}

Not Applicable.

\section{Competing interests}

The authors declare to have no competing interests: JCI; LCR; JMS; NA; BRL.

\section{Author details}

'Glaucoma Research Department, Instituto de Ojos Oftalmosalud, Lima, Peru. ${ }^{2}$ Glaucoma Department, Instituto de Ojos Oftalmosalud, Lima, Peru. ${ }^{3}$ Instituto de Ojos Oftalmosalud, Av. Javier Prado Este 1142, San Isidro, Lima, Peru.

Received: 13 March 2019 Accepted: 10 September 2020

Published online: 09 October 2020

\section{References}

1. Francis BA, Minckler D, Dustin $L$, et al. Combined cataract extraction and trabeculotomy by the internal approach for coexisting cataract and openangle glaucoma: initial results. J Cataract Refract Surg. 2008;34(7):1096-103. https://doi.org/10.1016/j.jcrs.2008.03.032

2. Fallano K, Bussel I, Kagemann L, Lathrop KL, Loewen N. Training strategies and outcomes of ab interno trabeculectomy with the trabectome. F1000Res. 2017;6. https://doi.org/10.12688/f1000research.10236.2.

3. SooHoo JR, Seibold LK, Kahook MY. Ab Interno trabeculectomy in the adult patient. Middle East Afr J Ophthalmol. 2015;22(1):25-9. https://doi.org/10. 4103/0974-9233.148345.

4. Tanito M. Microhook ab interno trabeculotomy, a novel minimally invasive glaucoma surgery. Clin Ophthalmol. 2018;12:43-8. https://doi.org/10.2147/ OPTH.S152406.

5. Wang C, Dang Y, Waxman S, Xia X, Weinreb RN, Loewen NA. Angle stability and outflow in dual blade ab interno trabeculectomy with active versus passive chamber management. PLoS One. 2017;12(5):e0177238. https://doi. org/10.1371/journal.pone.0177238.

6. Clement $\mathrm{Cl}$, Kampougeris G, Ahmed F, Cordeiro MF, Bloom PA. Combining phacoemulsification with endoscopic cyclophotocoagulation to manage cataract and glaucoma. Clin Exp Ophthalmol. 2013;41(6):546-51. https://doi. org/10.1111/ceo.12051.

7. Walland MJ, Parikh RS, Thomas R. There is insufficient evidence to recommend lens extraction as a treatment for primary open-angle glaucoma: an evidence-based perspective. Clin Exp Ophthalmol. 2012;40(4): 400-7. https://doi.org/10.1111/j.1442-9071.2011.02617.x.

8. $\quad$ Siegel MJ, Boling WS, Faridi OS, et al. Combined endoscopic cyclophotocoagulation and phacoemulsification versus phacoemulsification alone in the treatment of mild to moderate glaucoma. Clin Exp Ophthalmol. 2015;43(6):531-9. https://doi.org/10.1111/ceo.12510.

9. Lindfield D, Ritchie RW, Griffiths MF. "Phaco-ECP": combined endoscopic cyclophotocoagulation and cataract surgery to augment medical control of glaucoma. BMJ Open. 2012;2(3). https://doi.org/10.1136/bmjopen-2011000578.

10. Kaplowitz K, Bussel II, Honkanen R, Schuman JS, Loewen NA. Review and meta-analysis of ab-interno trabeculectomy outcomes. Br J Ophthalmol. 2016;100(5):594-600. https://doi.org/10.1136/bjophthalmol-2015-307131.

11. Rathi S, Radcliffe NM. Combined endocyclophotocoagulation and phacoemulsification in the management of moderate glaucoma. Surv Ophthalmol. 2017;62(5):712-5. https://doi.org/10.1016/j.survophthal.2017.01.011.

12. Morales J, Al Qahtani M, Khandekar R, et al. Intraocular pressure following phacoemulsification and endoscopic Cyclophotocoagulation for advanced Glaucoma: 1-year outcomes. J Glaucoma. 2015;24(6):e157-62. https://doi. org/10.1097/IJG.0000000000000228.

13. Lima FEL, de CDM, de AMP. Phacoemulsification and endoscopic cyclophotocoagulation as primary surgical procedure in coexisting cataract and glaucoma. Arq Bras Oftalmol. 2010;73(5):419-22.

14. Salinas L, Chaudhary A, Berdahl JP, et al. Goniotomy using the Kahook dual blade in severe and refractory Glaucoma: six month outcomes. J Glaucoma. 2018. https://doi.org/10.1097/IJG.0000000000001019.
15. Seibold LK, Soohoo JR, Ammar DA, Kahook MY. Preclinical investigation of ab interno trabeculectomy using a novel dual-blade device. Am J Ophthalmol. 2013;155(3):524-529.e2. https://doi.org/10.1016/j.ajo.2012.09.023.

16. Dang Y, Roy P, Bussel II, Loewen RT, Parikh H, Loewen NA. Combined analysis of trabectome and phaco-trabectome outcomes by glaucoma severity. F1000Res. 2016:5:762. https://doi.org/10.12688/f1000research.8448.2.

\section{Publisher's Note}

Springer Nature remains neutral with regard to jurisdictional claims in published maps and institutional affiliations.
Ready to submit your research? Choose BMC and benefit from:

- fast, convenient online submission

- thorough peer review by experienced researchers in your field

- rapid publication on acceptance

- support for research data, including large and complex data types

- gold Open Access which fosters wider collaboration and increased citations

- maximum visibility for your research: over $100 \mathrm{M}$ website views per year

At BMC, research is always in progress.

Learn more biomedcentral.com/submissions 